\title{
Facile electrosynthesis of nano flower like metal-organic framework and its nanocomposite with conjugated polymer as a novel and hybrid electrode material for highly capacitive pseudocapacitors
}

\author{
Maryam Naseria ${ }^{a}$ Lida Fotouhi $^{\text {a }}$, Ali Ehsani ${ }^{*}$ \\ ${ }^{a}$ Department of Chemistry, Alzahra University, Tehran, Iran \\ ${ }^{b}$ Department of Chemistry, Faculty of Science, University of Qom, Qom, Iran
}

*Corresponding author.

E-mail address:ehsani46847@yahoo.com

a.ehsani@qom.ac.ir 


\begin{abstract}
The $\left[\mathrm{Cu}(\mathrm{btec})_{0.5} \mathrm{DMF}\right] \quad\left(\mathrm{H}_{4} \mathrm{btec}=1,2,4,5\right.$-benzenetetracarboxylate acid $)$ was electrosynthesized on the graphite working electrode by applying catholic potential. The $\left[\mathrm{Cu}(\mathrm{btec})_{0.5} \mathrm{DMF}\right]$ grows on a graphite surface which results from the coordination of 1,2,4,5-benzenetetracarboxylate anions with $\mathrm{Cu}^{2+}$ cations. The electrosynthesized $\left[\mathrm{Cu}(\mathrm{btec})_{0.5} \mathrm{DMF}\right]$ was characterized by X-ray diffraction, scanning electron microscopy. Furthermore, POAP/ $\mathrm{Cu}(\mathrm{btec})_{0.5} \mathrm{DMF}$ nanocomposite film electrosynthesized on the surface of the carbon paste electrode by cyclic voltammetry. Different electrochemical methods including galvanostatic charge-discharge experiments, cyclic voltammetry and electrochemical impedance spectroscopy are carried out in order to investigate the performance of the system. This work introduces new nanocomposite materials for electrochemical redox capacitors with advantages including ease synthesis, high active surface area and stability in an aqueous electrolyte.
\end{abstract}

Keywords: electrochemical characterizations, electrodes, capacitors, MOF, nanocomposite 


\section{Introduction}

Polyaniline (PANI) is one of the most important conducting polymers because of its unique electrical, optical, and optoelectrical properties, as well as its ease of preparation and its excellent environment stability. Aminophenols are interesting members of the class of substituted anilines. The hydroxyl group in the phenyl ring can be oxidized to quinine and quinine can be reduced again. Poly ortho aminophenol (POAP) gives a surface film of interesting electrochemical and electrochromic properties when it is electropolymerised in acidic solution. This film is electroactive in aqueous and nonaqueous solutions containing protons but no response is observed at $\mathrm{pH}$-value higher than $\mathrm{pH}$ 7. The variety of results for conductivity of the POAP film reported in the literature [1-3] show that the electrochemical response of POAP is strongly influenced by the experimental procedure used to produce the polymer film, dopant anions and the purity starting monomer [1-4]. The electrical properties of conductive polymer could be modified by the addition of inorganic fillers. Nanoscale fillers are the most attractive, due to intriguing properties arising from the nanosize and large surface area. The insertion of nanoscale fillers may improve the electrical and dielectric properties of host conductive polymer materials.

Metal-organic frameworks (MOFs) are a new class of crystal porous materials consisted of metal ions coordinated to organic ligands, which were first introduced by Yaghi et al. [5, 6]. MOFs have attracted more and more attention due to their unique properties such as crystalline ordered structures, large surface areas, tunable pore sizes, high thermal stability, and chemical tenability [7-9]. Recently, MOFs have been widely 
applied in various fields such as gas adsorption/storage [10, 11], magnet [12], drug release [13], sensing [14, 15], catalysis [16], supercapacitors [17].

In the present work, for the first time to the best of our knowledge, we electrosynthesized $\left[\mathrm{Cu}(\mathrm{btec})_{0.5} \mathrm{DMF}\right]$ (Fig. 1) on the surface of graphite electrodes by applying a constant voltage to the solution of $\mathrm{H}_{4} b t e c$, metal ions and $\mathrm{NaNO}_{3}$. The experimental parameters, including applied voltage, the ratio of metal cation:ligand $\left(\mathrm{CuNO}_{3}: \mathrm{H}_{4}\right.$ btec $)$, and reaction time, were optimized in order to achieve the highest purity and lowest metal plating. Furthermore, room temperature electrochemically synthesized POAP/ $\mathrm{Cu}(\mathrm{btec})_{0.5} \mathrm{DMF}$ electrode is presented as an efficient potential candidate in supercapacitor application. Our goals in this paper were increasing the capacitance of POAP electrode by using $\mathrm{Cu}(\mathrm{btec})_{0.5} \mathrm{DMF}$ to form a composite electrode and moreover increase the cycle ability of the electrode. The capacitive behavior of nanocomposite was tested by cyclic voltammetry, galvanostatic charge discharge and impedance spectroscopy techniques.

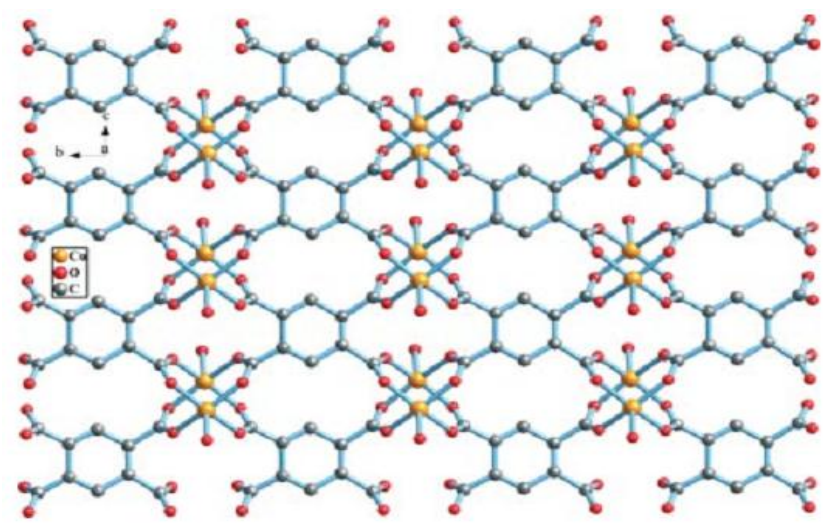

Figure 1. Molecular structure of $\mathrm{Cu}(\mathrm{btec})_{0.5} \mathrm{DMF}$. 


\section{Experimental}

\subsection{Reagent and materials}

All the chemical materials used in this work, obtained from Merck Chemical Co., were of analytical grade and used without further purification. Double distilled water was used throughout the experiments.

\subsection{Characterisation}

All electrochemical experiments were carried out by an Autolab General Purpose System PGSTAT 30 (Eco-chime, Netherlands). A conventional three electrode cell with an $\mathrm{Ag} / \mathrm{AgCl}$ reference electrode (Argental, $3 \mathrm{M} \mathrm{KCl}$ ) was used in order to carry out the electropolymerization of the POAP. A platinum wire and a carbon paste electrode was used as the counter and working electrodes respectively. Morphological investigations of the polymeric films were carried out by using SEM analysis.

\subsection{Synthesis of $\mathrm{Cu}(\mathrm{btec})_{0.5} \mathrm{DMF}$}

Two graphite electrodes as working and auxiliary and $\mathrm{Ag} / \mathrm{AgCl}$ electrode as a reference electrode were used for the electrosynthesis of $\left[\mathrm{Cu}(\mathrm{btec})_{0.5} \mathrm{DMF}\right]$. The optimal values of organic linker $\left(0.1 \mathrm{M} \mathrm{H} \mathrm{H}_{4} \mathrm{btec}\right)$, copper nitrate $(0.02 \mathrm{M})$, sodium nitrate $(0.1 \mathrm{M})$ and supporting electrolyte $(0.1 \mathrm{M}$ tetrabutylammonium tetrafluroborat (TBTA)) were dissolved in DMF: water (100:1 V/V) solution. Electrolysis was carried out in an electrochemical cell under optimal constant voltage electrolysis $(-1.7 \mathrm{~V})$ for $10 \mathrm{~min}$. Finally the green precipitate of $\left[\mathrm{Cu}(\mathrm{btec})_{0.5} \mathrm{DMF}\right]$ was deposited on the graphite surface. 


\subsection{Synthesis of POAP and POAP/ $\mathrm{Cu}(\text { btec })_{0.5} D M F$ nanocomposites}

POAP/ $\mathrm{Cu}(\mathrm{btec}) 0.5 \mathrm{DMF}$ composites were prepared by in a stirring solution containing $0.01 \mathrm{M}$ monomer, $0.5 \mathrm{M} \mathrm{HClO}_{4}, 0.1 \mathrm{M} \mathrm{LiCO}_{4}$ and $5.0 \times 10^{-3} \mathrm{M}$ sodium dodecyl sulfate (SDS) on the surface of the $\mathrm{Cu}(\mathrm{btec})_{0.5} \mathrm{DMF}(3 \% \mathrm{w} / \mathrm{w})$ modified carbon paste electrode. POAP electrode was synthesized in same solution without $\mathrm{Cu}(\mathrm{btec})_{0.5} \mathrm{DMF}$ nanoparticles. Electropolymerizations were conducted by 40 consecutive cycles at the sweep rate of $50 \mathrm{mV} \cdot \mathrm{s}^{-1}$ in the potentials between -0.5 to $1.0 \mathrm{~V}$. The mass of POAP films was approximated assuming a current efficiency for the electropolymerization process of $100 \%$, using Faraday's law.

\section{Results and discussion}

Analysis of the resulting $\mathrm{Cu}(\mathrm{btec})_{0.5} \mathrm{DMF}$ compound by X-ray powder diffraction revealed that the solid was pure $\left[\mathrm{Cu}(\mathrm{btec})_{0.5} \mathrm{DMF}\right]$ by comparison with the pattern simulation [18] from the crystal structure (Fig. 2). However, some differences were also observed between experimental and simulated patterns. Such differences in intensities in MOFs are common $[19,20]$ since the structure is modeled in the absence of guests in the pores, while the simulated pattern is obtained in the presence of the solvent, thus having guests in the pores, which affects the peak intensities and positions. 


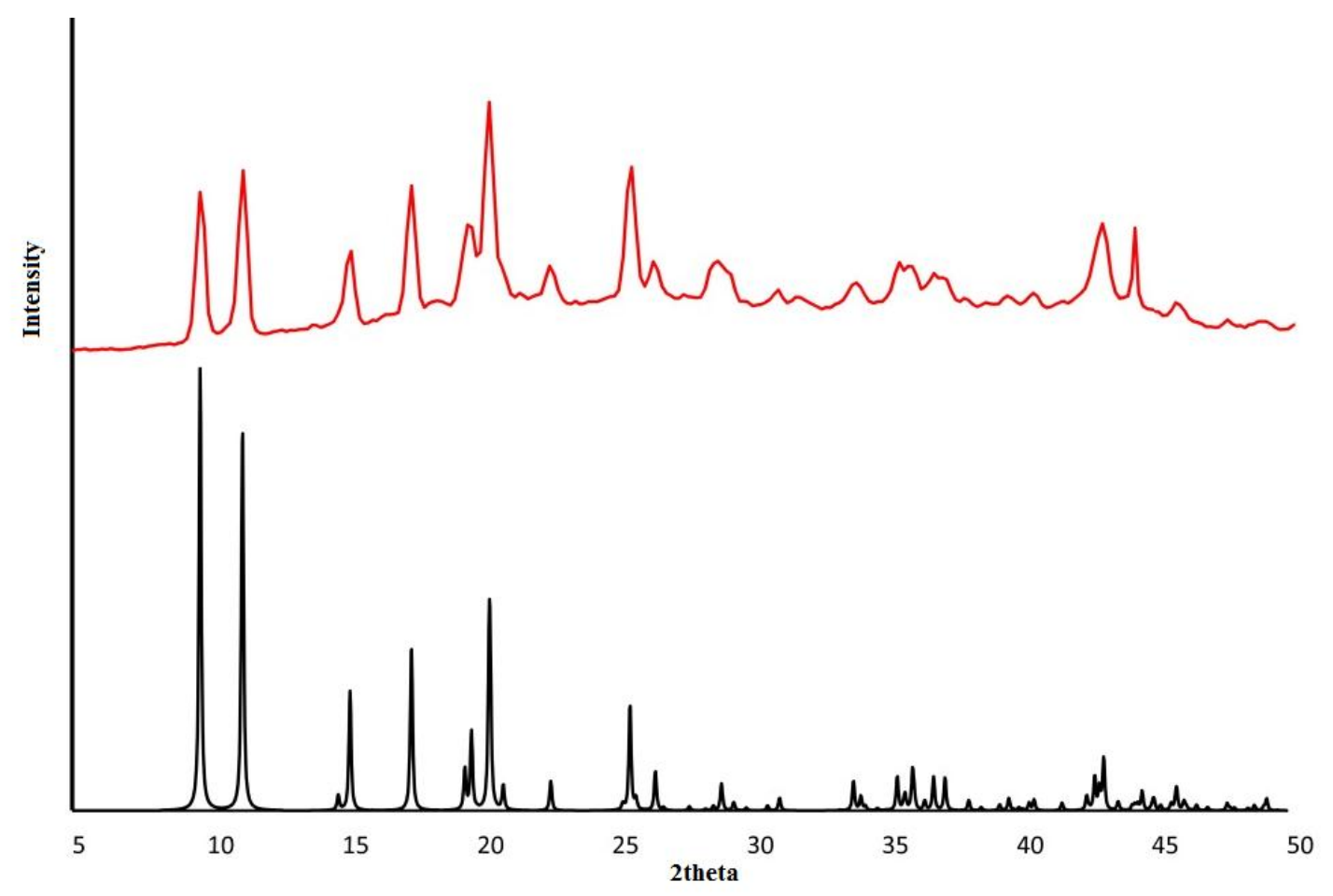

Fig. 2. XRD pattern of electrosynthesized $\mathrm{Cu}(\mathrm{btec})_{0.5} \mathrm{DMF}$.

The microstructures of the MOF samples were observed through scanning electron microscopy. Fig. 3 shows the SEM image of the electrochemically synthesized $\left[\mathrm{Cu}(\mathrm{btec})_{0.5} \mathrm{DMF}\right]$ under optimized experimental conditions. The electrosynthesized MOF bundles strongly resemble natural flowers. Short synthesis time in addition to accelerated nucleation in electrosynthesis seems to make particles more porous and smaller. The SEM image shows the morphology of $\left[\mathrm{Cu}(\mathrm{btec})_{0.5} \mathrm{DMF}\right]$ to be uniform nanoflower arrays with monomodal particle size distribution of $40-50 \mathrm{~nm}$ on average. The inset of the top right corner of Fig. 3 shows a high magnification of an assembled 3D flower nanostructure particle. A single "flower" consists of petal needle-like crystals radiating from the center. 


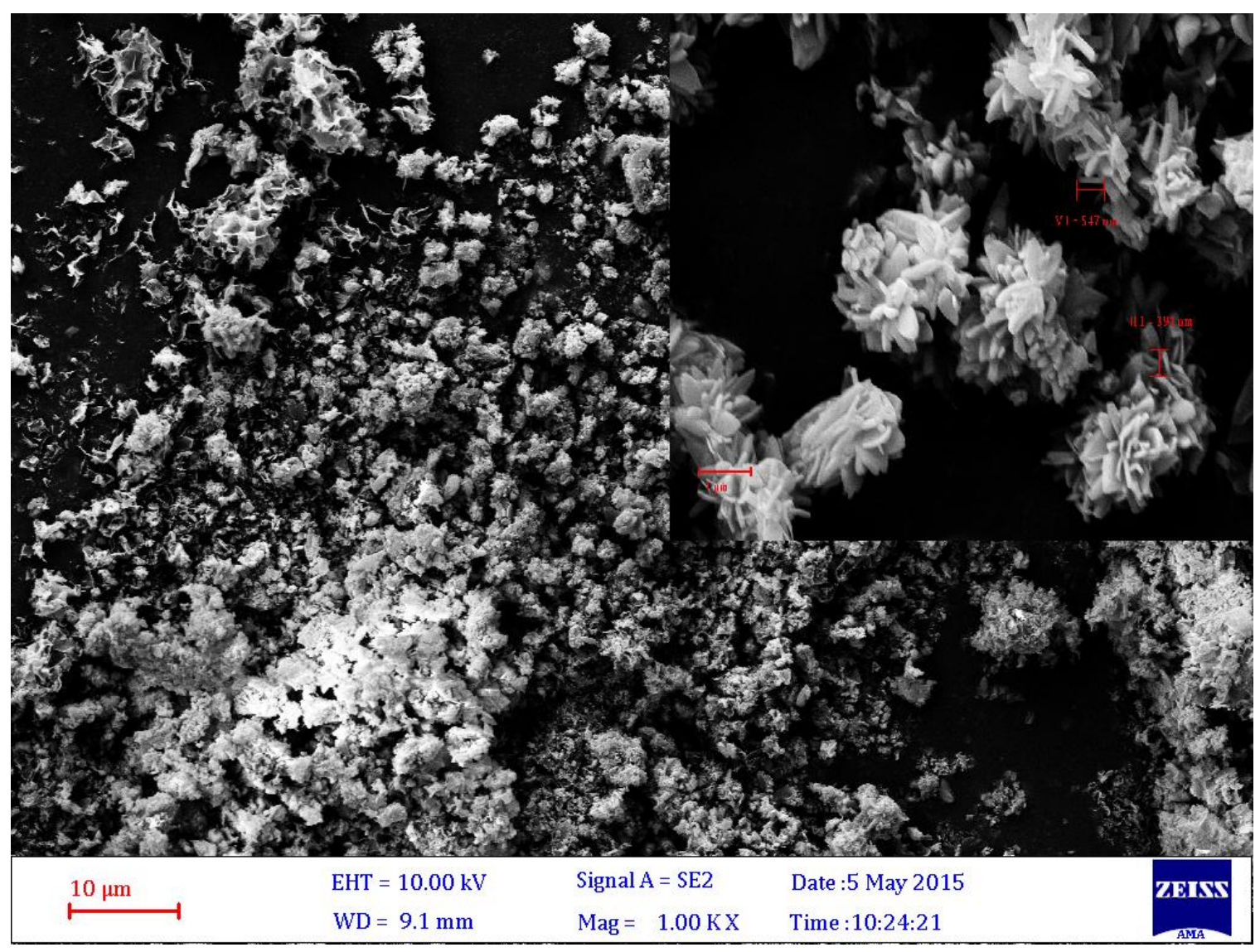

Fig. 3. SEM image of the electrochemically synthesized $\left[\mathrm{Cu}(\mathrm{btec})_{0.5} \mathrm{DMF}\right]$ under

optimized experimental conditions. 
SEM image of electrosynthesized POAP/ $\mathrm{Cu}(\mathrm{btec}) 0.5 \mathrm{DMF}$ have been shown in figure 4. It can be seen from the SEM image of composite film that the synthesized composite film has nanostructured size and porous structure.

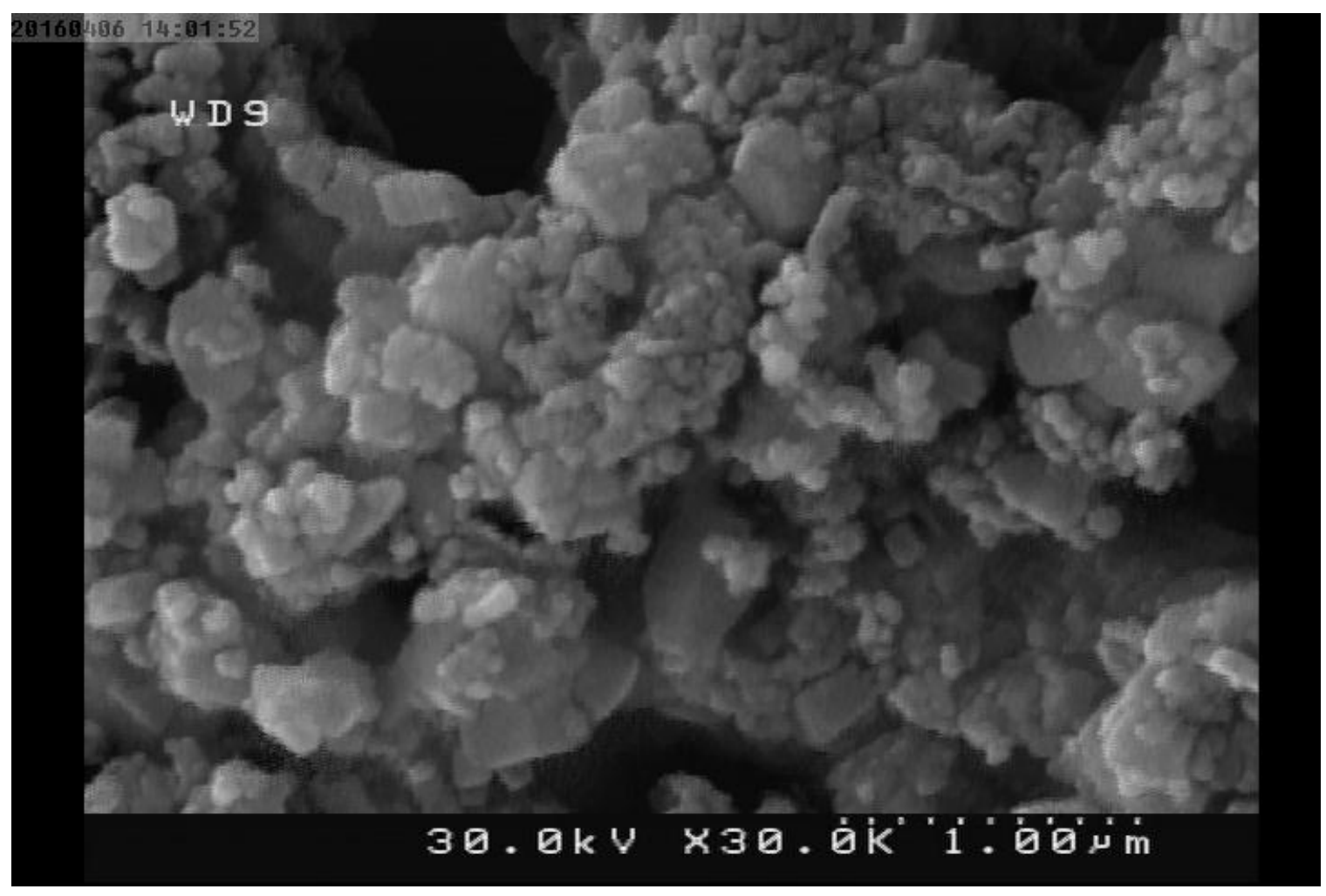

Figure 4. SEM image of $\mathrm{POAP} / \mathrm{Cu}(\mathrm{btec}) 0.5 \mathrm{DMF}$ composite film.

To elucidate the effect of $\mathrm{Cu}(\mathrm{btec})_{0.5} \mathrm{DMF}$ on the property of POAP films, electrochemical performance of composite films was evaluated by carrying out $\mathrm{CV}$ measurements in $0.5 \mathrm{M} \mathrm{HClO}_{4}$, as shown in Fig. 5. The cyclic voltammograms of the POAP/ $\mathrm{Cu}(\mathrm{btec})_{0.5} \mathrm{DMF}$ films showed a couple of strong and broad oxidation and reduction waves. Their wave currents were higher than that of pure POAP films electrodes. The voltammetric behavior of both films is similar and the CV curves show the voltammograms reveal the electrodes are stable in $\mathrm{HClO}_{4}$ solution within the 
sweeping potential range. Close comparisons of CV curves between POAP/ $\mathrm{Cu}(\mathrm{btec})_{0.5} \mathrm{DMF}$ electrode and pure POAP electrode show that a POAP/ $\mathrm{Cu}(\mathrm{btec})_{0.5} \mathrm{DMF}$ electrode not only displays a higher background current in the potential sweep but also there exist faradic currents, which are believed to arise from the contribution of the loaded $\mathrm{Cu}(\mathrm{btec})_{0.5} \mathrm{DMF}$. One possible explanation for the higher current is the increase in the concentration of OAP monomers near the electrode surface due to the influence of $\mathrm{Cu}(\mathrm{btec})_{0.5} \mathrm{DMF}$. This is supported by the fact that the adsorption of positively charged ions of monomer on the surface of the nanoparticles is likely due to their negative zetapotential value in aqueous solutions at $\mathrm{pH} 2$. The z-potential values becomes slightly less negative when the positively charged OAP monomers are adsorbed on the surface of the $\mathrm{Cu}(\mathrm{btec})_{0.5} \mathrm{DMF}$ and they became carriers of OAP increasing their concentration near the electrode surface and therefore the polymerization rate. Other reasons for the current increase could be that the increase of available area due to the incorporation of the $\mathrm{Cu}(\mathrm{btec})_{0.5} \mathrm{DMF}$. 


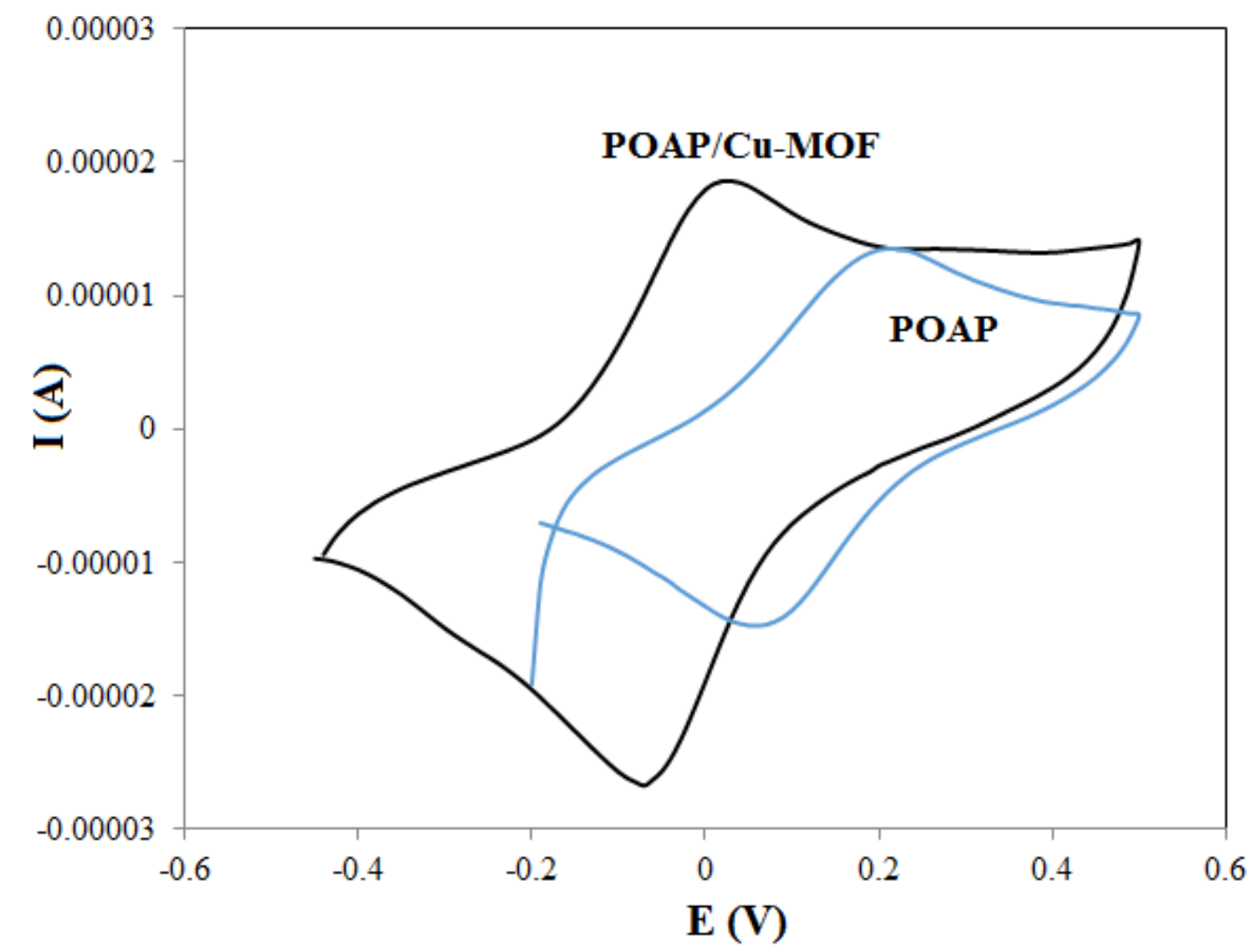

Fig. 5. Cyclic voltammograms of the POAP and POAP/ $\mathrm{Cu}(\mathrm{btec})_{0.5} \mathrm{DMF}$ films in the monomer free solution $\left(0.5 \mathrm{M} \mathrm{HClO}_{4}\right)$.

Fig. 6 shows the cyclic voltammograms of POAP/ $\mathrm{Cu}(\mathrm{btec})_{0.5} \mathrm{DMF}$ films at different scan rates in acidic solution. A pair of peaks signifying polymers redox processes are present in studies. In various scan rates by ploting $i_{\text {peak }}$ vs scan rate in a $\log -\log$ diagram, we obtain $\alpha$ from the slope of a linear fit to the data. The parameter $\alpha$ is related to the fractal dimension $\left(\mathrm{D}_{\mathrm{f}}\right)$ of the surface through [21].

$I_{p} \propto \vartheta^{\alpha}$ 


$$
\alpha=\frac{D_{f}-1}{2}
$$

The data points lie on a straight line in the log-log diagram, and the slope gives $\alpha$ of the straight line. Substituting $\alpha$ value in the Eq. (2) we obtain the fractal dimension of the composite film around 2.43. Fractal geometry is a mathematical concept that describes objects of irregular shape. Some natural geometrical shapes, that can be irregular, tortuous, and rough or fragmented, can be described using concepts of fractal geometry as long as the requirement of self-similarity is satisfied. Moreover, fractal geometry provides a powerful opportunity to investigate surface roughness via geometrical model [1]. The term fractal indicates the fact that the material of interest has a fractional dimension, not a whole number value, and the term was specifically applied for temporal and spatial phenomena that exhibit partial correlations over many scales. Fractal dimension $\left(\mathrm{D}_{\mathrm{f}}\right)$ is a quantitative parameter for analysis of fractal objects, which is widely used for different purposes. In addition, it is one of the most important and useful parameters for analysis of structure of rough surfaces. 


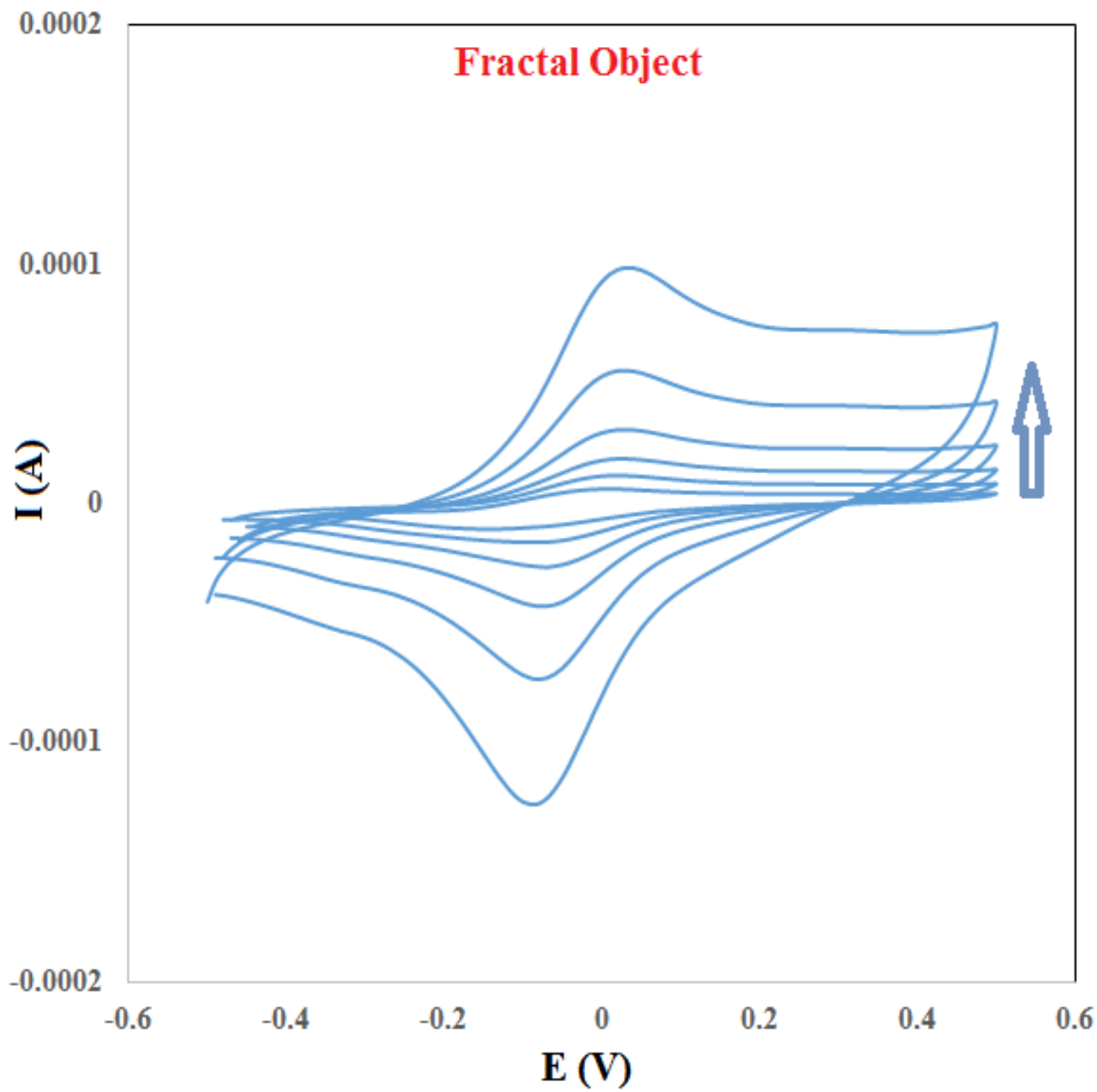

Fig. 6. Cyclic voltammograms of $\mathrm{POAP} / \mathrm{Cu}(\mathrm{btec})_{0.5} \mathrm{DMF}$ films in different scan rates

$$
\left(10-400 \mathrm{mv} \cdot \mathrm{s}^{-1}\right) \text {. }
$$

Galvanostatic charge/discharge method has been used to highlight the capacitance characteristic of $\mathrm{POAP} / \mathrm{Cu}(\mathrm{btec})_{0.5} \mathrm{DMF}$ composite electrode. Figure 7 shows the charge/discharge behavior of POAP and POAP/ $\mathrm{Cu}(\mathrm{btec})_{0.5} \mathrm{DMF}$ electrodes in the potential range from 0.0 to $0.6 \mathrm{~V}$. As it can be seen, a triangular shape between this potential ranges is observed that indicating good columbic efficiency and ideal capacitive 
behavior of POAP/ $\mathrm{Cu}(\mathrm{btec})_{0.5} \mathrm{DMF}$ as electrode for application in pseudo supercapacitor.

One of the most important parameters for practical application is cycling stability. Figure 8 shows the stability POAP/ $\mathrm{Cu}(\mathrm{btec})_{0.5} \mathrm{DMF}$ composite electrodes when cycled at a current $1 \mathrm{~mA}$ for 1000 cycles. Stability of electrodes is compared in terms of losing their capacities as stability percentage. The stability of electrode calculated from following equation:

Stability $=\mathrm{C}_{\mathrm{n}} / \mathrm{C}_{1} \times 100$

$\mathrm{C}_{\mathrm{n}}$ is the capacitance of electrode in each cycles and $\mathrm{C}_{1}$ is capacitance of electrode in the first cycle. Results shows, using POAP/ $\mathrm{Cu}(\mathrm{btec})_{0.5} \mathrm{DMF}$ in POAP caused an excellent retention in stability percentage of composite electrode suggesting the good stability toward long time charge-discharge applications. While the POAP electrode loses its stability fast, composite electrode maintains its stability and saves more that $90 \%$ of its capacitance of the first cycle under consecutive cycles after 1000 cycles.

Specific capacitance (C) of composite electrode is calculated from galvanostatic charge/discharge curves using the following equation [22]:

$$
C=\frac{I \Delta t}{\Delta V m}
$$

Where $\mathrm{I}$ is the current loaded, $\mathrm{m}$ is reactive material mass, $\mathrm{V}$ is the potential change during discharge process and $\mathrm{t}$ is the discharge time. The mass of deposited polymer on electrode was calculated from the charge (Q) passed during characteristic CV of electrode (Fig. 4) based on Faraday's law: $\mathrm{Q}=\mathrm{znF}$, where $\mathrm{Q}$ is the difference of passed charge through polymer electrodes, $\mathrm{z}$ is the number of exchanged electrons and $\mathrm{n}$ is the number 
of moles. By substituting the obtained mass value in equation 4, the specific capacitance of POAP/ $\mathrm{Cu}(\mathrm{btec})_{0.5} \mathrm{DMF}$ electrode was found to be $241 \mathrm{~F}^{-\mathrm{g}^{-1}}$.
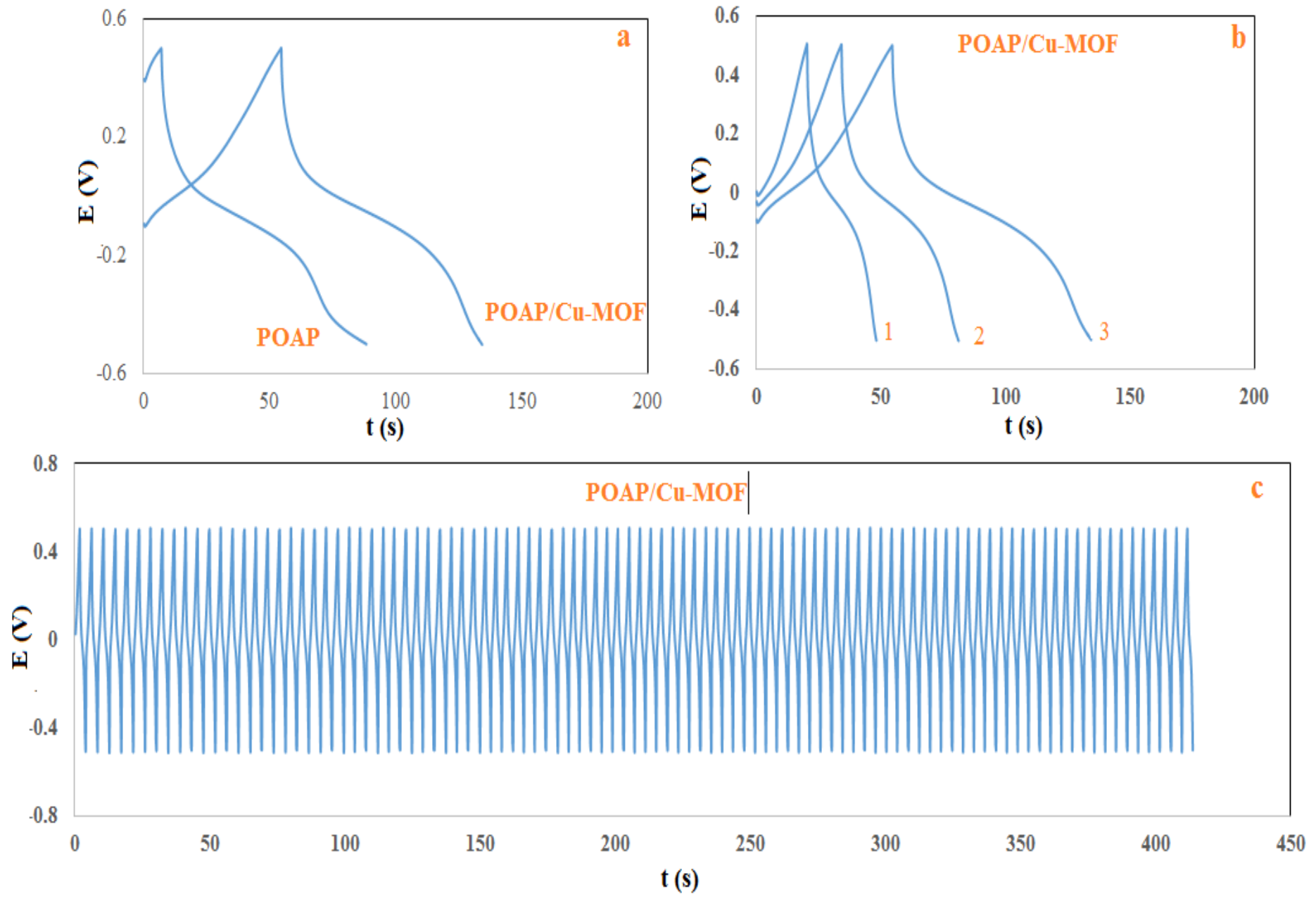

Figure 7. Galvanostatic charge and discharge measurements of (a) POAP and POAP/ $\mathrm{Cu}$ (btec) ${ }_{0.5} \mathrm{DMF}$ electrode in $0.1 \mathrm{M} \mathrm{HClO}_{4}$ solution at $0.005 \mathrm{~mA}$, (b) different current (0.005-0.01mA) for composite and (c) during consecutive charge-discharge of composite film. 


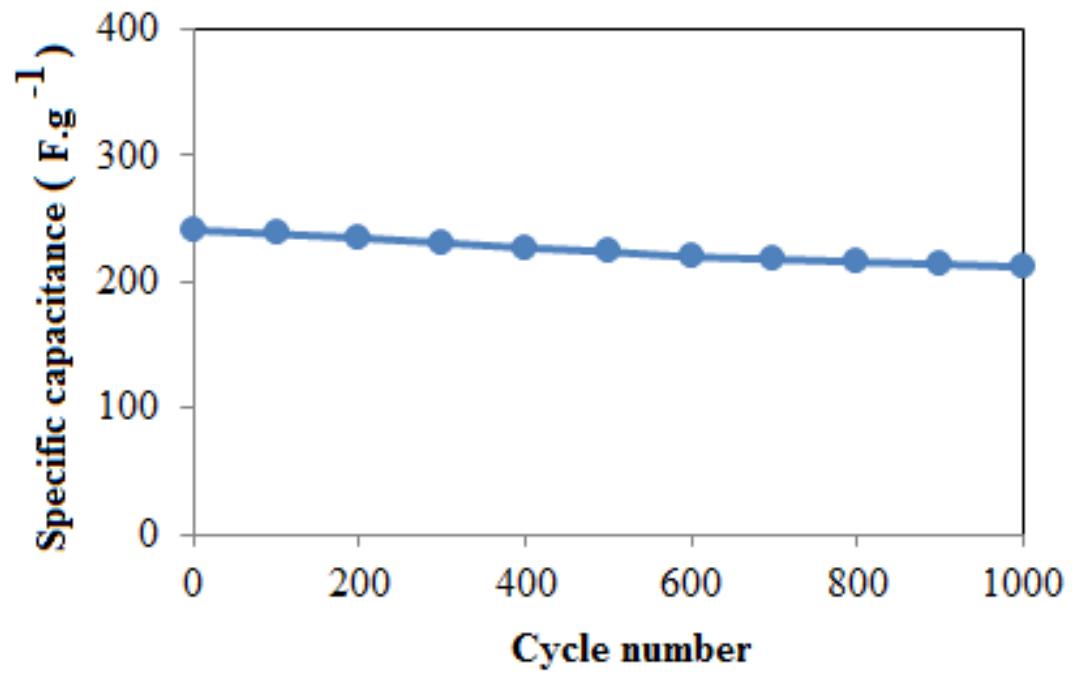

Figure 8. Cycle stability of $\mathrm{POAP} / \mathrm{Cu}(\mathrm{btec})_{0.5} \mathrm{DMF}$ composite electrode.

Electrochemical impedance spectroscopy (EIS) is one of the best techniques for analyzing the properties of conducting polymer electrodes and it has been broadly discussed in the literature using a variety of theoretical models [23-28]. In the case of electrochemical system, EIS can reveal information regarding processes occurring in the polymer matrix when it is doped. This may include kinetic values of the doping process and parameters of the diffusion of ions into the polymers. Electrochemical impedance spectroscopy was analyzed by the frequency ranging from $0.1 \mathrm{HZ}$ to $100 \mathrm{kHz}$. As shown in Fig 9, the Nyquist plots consist of an arc and a straight line. The semicircle observed in the higher frequency region attributes to the interfacial charge transfer resistance while the straight line indicates a capacitive behavior related to the charging mechanism [2934]. No obvious semicircle was observed at the frequency range, this suggests that the electron transfer resistance can be neglected, because of the high conductivity [35]. The straight line of $\mathrm{POAP} / \mathrm{Cu}(\mathrm{btec})_{0.5} \mathrm{DMF}$ is more close to vertical line in the impedance 
spectra at low frequencies, suggesting that the composites have better capacitor behavior than POAP. These results are consistent with the above data, which could be concluded that $\mathrm{Cu}(\mathrm{btec})_{0.5} \mathrm{DMF}$ embedded in POAP leads to a better capacitive performance.

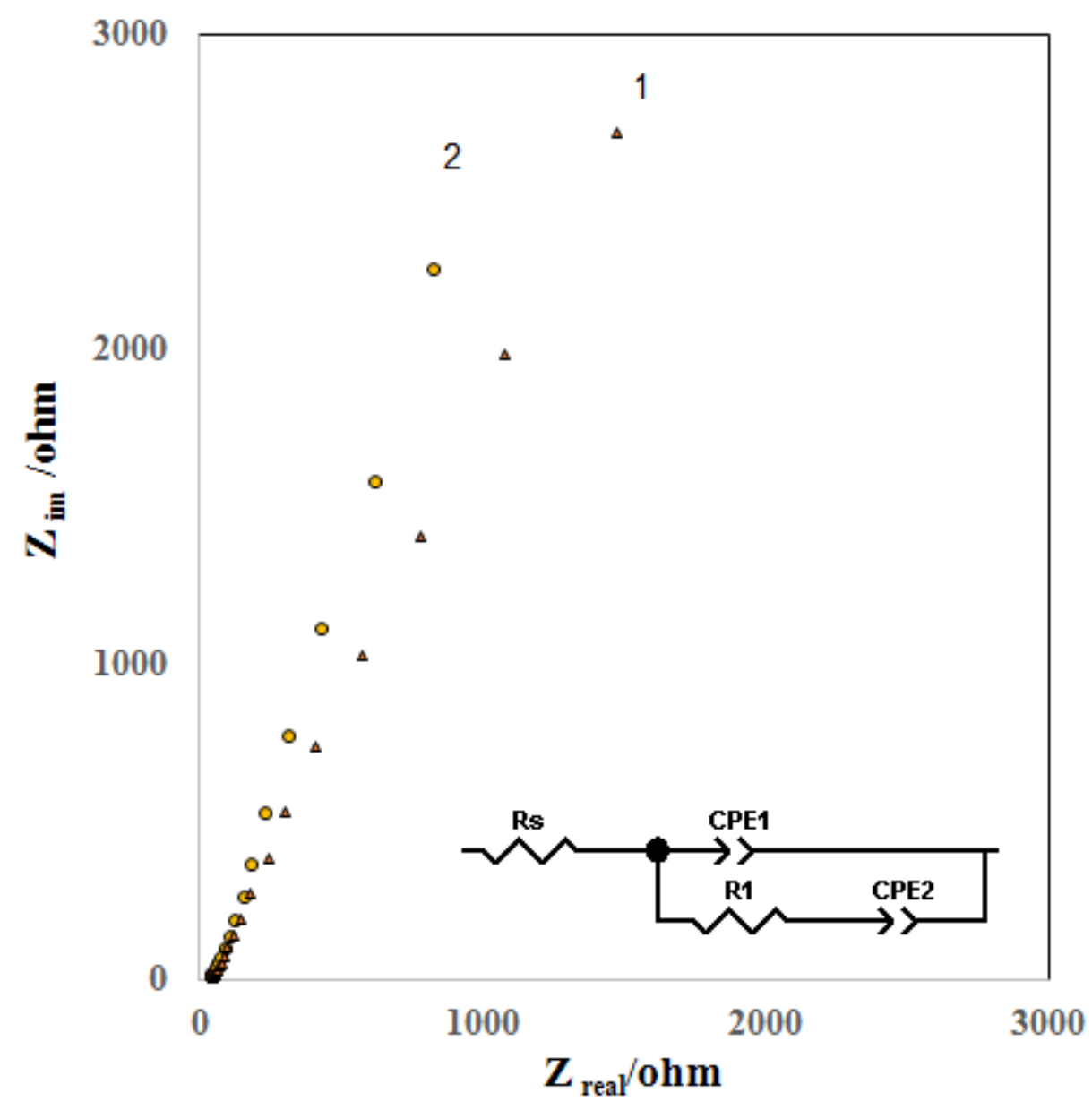

Figure 9. Nyquist plots recorded from $0.1 \mathrm{HZ}$ to $100 \mathrm{kHz}$ with ac amplitude of $5 \mathrm{mV}$ for POAP (1) and POAP/ $\mathrm{Cu}(\mathrm{btec})_{0.5} \mathrm{DMF}$ (2) electrode. 


\section{Conclusions}

In summary, $\left[\mathrm{Cu}(\mathrm{btec})_{0.5} \mathrm{DMF}\right]$ has been electrosynthesized on the surface of graphite electrodes by applying a constant voltage to the solution of $\mathrm{H}_{4}$ btec, metal ions and $\mathrm{NaNO}_{3}$. We have synthesized a kind of novel conductive polymer /MOF composite film by using a simple and general strategy namely in situ electropolymerization on the surface of the working electrode. The electrochemical behavior shows that the POAP/ $\mathrm{Cu}(\mathrm{btec})_{0.5} \mathrm{DMF}$ composites possess excellent electrochemical stability with $91 \%$ of its initial capacitance retained after 1000 charge/discharge cycles. The enhancement of electrochemical performance of the POAP/ $\mathrm{Cu}(\mathrm{btec})_{0.5} \mathrm{DMF}$ composite originate from the high specific surface area for / $\mathrm{Cu}(\mathrm{btec})_{0.5} \mathrm{DMF}$. Therefore , The $\mathrm{Cu}(\mathrm{btec})_{0.5} \mathrm{DMF}$ has an obvious improvement effect, which makes the composites have more active sites for faradic reaction and larger specific capacitance than pure POAP.

\section{Acknowledgements}

The authors would like to express their deep gratitude to the Iranian Nano Council for supporting this work. 


\section{References}

[1] A. Ehsani, MG. Mahjani,M. Jafarian, A. Naeemy, Prog. Org. Coat, 69(2010) 510.

[2] A. Ehsani, M.G. Mahjani, M. Jafarian, Synth. Met, 162(2012) 199.

[3] A. Ehsani, M.G. Mahjani, M. Jafarian, Synth. Met, 161(2011) 1760.

[4] A. Ehsani, M.G. Mahjani, M. Bordbar, S. Adeli J. Electroanal. Chem. 710 (2013) 2935 .

[5] O. M. Yaghi, H. Li, J. Am. Chem. Soc. 117(1995) 10401.

[6] H. Li, M. Eddaoudi, M. O_Keeffe, O. M. Yaghi, Nature, 402(1999) 276.

[7] J. R. Long, O. M. Yaghi, Chem. Soc. Rev. 38(2009) 1213.

[8] K. Xi, S. Cao, X. Peng, C. Ducati, R. V. Kumar, A. K. Cheetham, Chem. Commun. 49(2013) 2192.

[9] O. K. Farha, J. T. Hupp, Acc. Chem. Res. 43(2010) 1166.

[10] S. Couck, J. Denayer, G. Baron, T. Re_my, J. Gascon, F. Kapteijn, J. Am. Chem. Soc. 131(2009) 6326.

[11] S. S. Kaye, A. Dailly, O. M. Yaghi and J. R. Long, J. Am. Chem. Soc. 2007, 129, 14176.

[12] J. Cao, K. X. Shang, W. T. Deng, Inorg. Chem. Commun. 29(2013) 183.

[13] J. An, S. J. Geib, N. L. Rosi, J. Am. Chem. Soc. 131(2009) 8376.

[14] M. D. Allendorf, C. A. Bauer, R. K. Bhaktaa, R. J. T. Houka, Chem. Soc. Rev. 38(2009) 1330.

[15] B. V. Harbuzaru, A. Corma, F. Rey, J. Jord, D. Ananias, L. Carlos, J. Rocha, Angew. Chem. Int. Ed. 48 (2009) 6476.

[16] N. T.S. Phan, P. H. L. Vu, T. T. Nguyen, J. Catal. 306(2013) 38.

[17] R. D_az, M. G. Orcajo, J. A. Botas, Mater. Lett. 68(2012)126. 
[18] H.K. Zhao, B. Ding, E.C. Yang, X.G. Wang, X.J. Zhao, Z. Anorg. Allg. Chem. 633 (2007) $1735-1738$.

[19] O.K. Farha, A.Ö. Yazaydın, I. Eryazici, C.D. Malliakas, B.G. Hauser, M.G. Kanatzidis, S.T. Nguyen, R.Q. Snurr, J.T. Hupp, Nat. Chem. 2 (2010) 944-948.

[20] D.J. Tranchemontagne, J.R. Hunt, O.M. Yaghi, Tetrahedron 64 (2008) 8553-8557.

[21] H. Mohammad Shiri, A. Ehsani , J. Collid and Interface Science, 5 (2016) 91062.

[22] A. Ehsani, H. Mohammad Shiri, E. Kowsari, R. Safari, J. Torabian, S. Kazemi, J. Colloid and Interface Science, 478 (2016)181-187.

[23] N. Salehifar, J. Shabani Shayeh, SO. Ranaei Siadat, K. Niknam, A. Ehsani, S. Kazemi Movahhed, RSC Adv, 5 (2015) 96130 - 96137.

[24] J. Shabani-Shayeh, A. Ehsani, MR. Ganjali, P. Norouzi, B. Jaleh, Appl. Surf. Sci., 353(2015) 594.

[25] J. Shabani Shayeh, P. Norouzi, M.R. Ganjali, RSC Advances, 5(2015) 20446-20452.

[26] J. Shabani-Shayeh, A. Ehsani, A. Nikkar, P. Norouzi, M. R. Ganjali, M. Wojdyla, New. J. Chem, 39( 2015) 9454.

[27] H. Mohammad Shiri, A. Ehsani, J. Shabani Shayeh, RSC Advances, 5(2015)9106291068.

[28] H. Heli, H. Yadegari, A. Jabbari, Materials Chemistry and Physics, 134 (2012) 2125.

[29] A. Ehsani, M.G. Mahjani, S. Adeli, S. Moradkhani, Prog. Org. Coat. 77(2014) 1674.

[30] A. Ehsani, F. Babaei, H. Mostaanzadeh, J. Braz. Chem. Soc, 26(2015) 331.

[31] M. Naseri, L. Fotouhi, A. Ehsani , F. Babaei, New. J. Chem, 40 (2016)2565-2573. 
[32] A. Ehsani, M G. Mahjani, F. Babaei, H. Mostaanzadeh, RSC Adv, 5 (2015) 30394 30404.

[33] A. Ehsani, A. Vaziri-Rad, F. Babaei, H. Mohammad Shiri, Electrochim. Acta, 159 (2015) 140-148.

[34] K. Kakaei, M. Hamidi, S. Husseindoost, Journal of Colloid and Interface Science, 479(2016) 121-126.

[35] K. Zhang, LL. Zhang, X.S. Zhao, JS. Wu, Chem. Mater, 22(2010) 1392. 


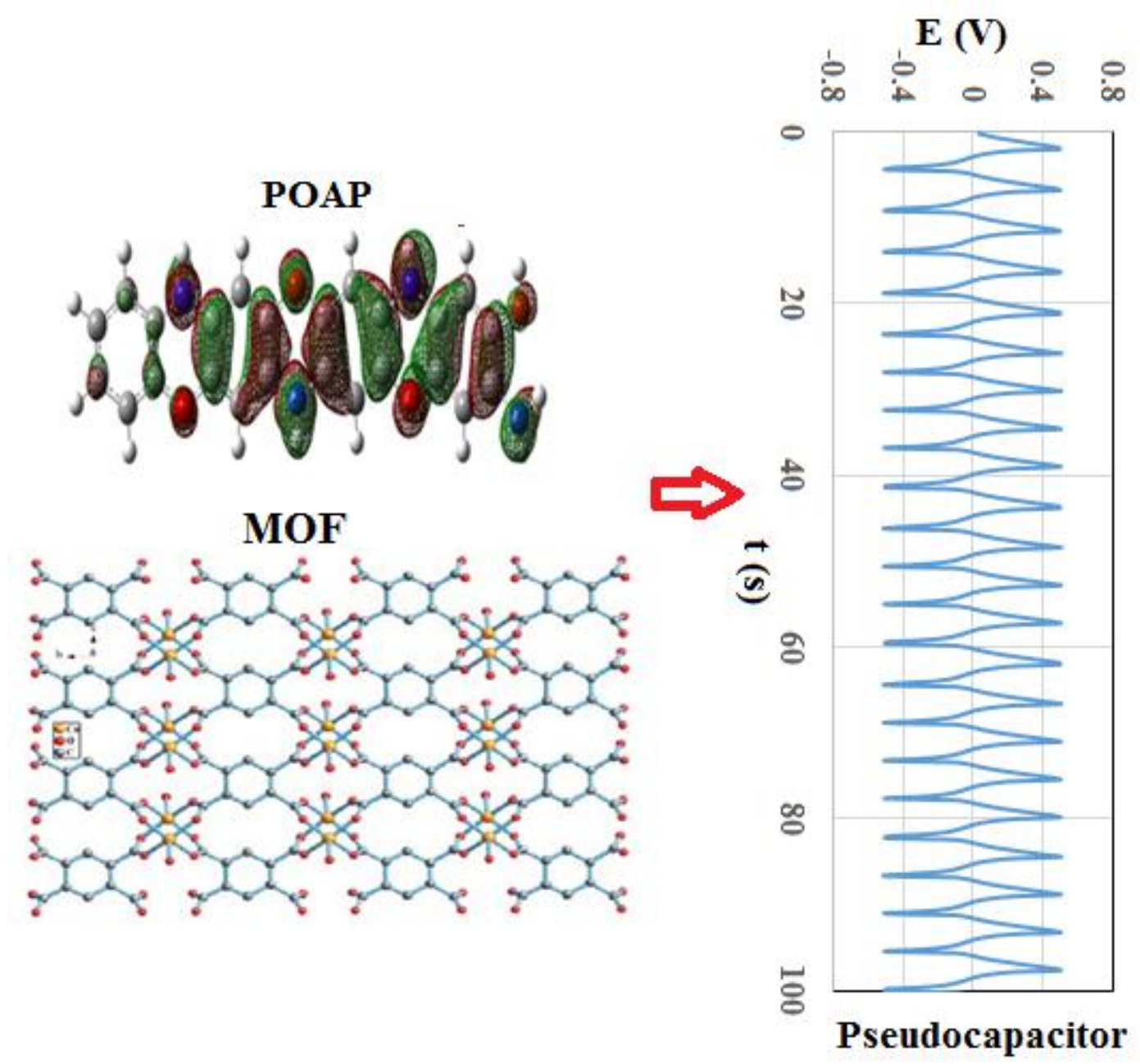

